\title{
Oral Health Status among Madrasa going Children in Selected Areas of Dhaka City, Bangladesh
}

${ }^{1}$ Mohammad Khan, ${ }^{2}$ Shamima Easmin Nishi, ${ }^{3}$ Sumaiya Jabin Yusufzai, ${ }^{4}$ Nafij Bin Jamayet, ${ }^{5}$ Mohammad Khursheed Alam

\begin{abstract}
Dental caries affect humans of all ages, including all regions of the world and is a disease of the complex interplay of social, behavioral, cultural, dietary, and biological risk factors. The objective of this study was to determine the oral hygiene status and the prevalence of decayed, missing, and filled number of teeth (DMFT index) among madrasa going children of selected area of Dhaka city, Bangladesh. A descriptive type of crosssectional study was conducted by a purposeful selection of some madrasa with a sample size of 251. Data collection were done by four sections. Section one, two and three consist of structured questionnaire and section four resembles to DMFT index which were measured by clinical examination using an examination form. Seventy percent of children had experienced dental caries with mean DMFT score of 1.94. Female children had higher DMFT score than male children. There was a highly significant association between tooth brushing frequency and family income of respondents with caries. We conducted this study in madrasa because up till now such study has not been performed. These data on oral health status and prevalence of DMFT will certainly helps to determine the appropriate treatment plan for madrasa going children. For the benefit of a community, dental health programs need to be conducted repeatedly in order to reach the goals of the World Health Organization (WHO).
\end{abstract}

Keywords: Bad breath, DMFT, Gum bleeding, Madrasa students, Tooth brushing.

How to cite this article: Khan M, Nishi SE, Yusufzai SJ, Jamayet NB, Alam MK. Oral Health Status among Madrasa going Children in Selected Areas of Dhaka City, Bangladesh. Int J Experiment Dent Sci 2016;5(1):45-49.

Source of support: Nil

Conflict of interests: None

${ }^{1,2} \mathrm{PhD}$ Student, ${ }^{3-5}$ Senior Lecturer

${ }^{1}$ Department of Dental Public Health, School of Dental Sciences, Universiti Sains, Kubang Kerian, Kelantan, Malaysia

${ }^{2,5}$ Department of Orthodontic Unit, School of Dental Sciences Universiti Sains, Kubang Kerian, Kelantan, Malaysia

${ }^{3}$ Department of Public Health, Northern University, Dhaka Bangladesh

${ }^{4}$ Department of Maxillofacial Prosthesis, School of Dental Sciences, Universiti Sains, Kubang Kerian, Kelantan, Malaysia

Corresponding Author: Mohammad Khan, PhD Student Department of Dental Public Health, School of Dental Sciences Universiti Sains, Kubang Kerian, Kelantan, Malaysia, Phone: +60142926987, e-mail: drmohammadkhan1001@gmail.com

\section{INTRODUCTION}

Bangladesh, a developing country faces many challenges in rendering oral health needs. In Bangladesh, approximately $32.3 \%$ of whole population belongs to $0-14$ years (male: $27,268,560$; female: $26,468,883$ ) respectively. ${ }^{1}$ Among all, $30 \%$ of school going children are enlisted in madrasa. ${ }^{2}$ According to World Health Organization (WHO), oral health is a state of being free from chronic mouth and facial pain, oral and throat cancer, oral sores, birth defects, such as cleft lip and palate, periodontal (gum) disease, tooth decay and tooth loss, and other diseases and disorders that affect the oral cavity. ${ }^{3}$ Dental caries and periodontal disease are the most commonly seen oral disease which shows striking geographic variation, socioeconomic patterns and severity of distribution all over the world. ${ }^{4}$ Dental caries is a multifactorial oral disease developed by the localized dissolution of the tooth hard tissues, caused by bacteria. ${ }^{5}$ In low-income countries, dental caries is the most prevalent oral disease of public health concern. ${ }^{6}$ Dental caries affects humans of all ages, including all regions of the world and is a disease of the complex interplay of social, behavioral, cultural, dietary, and biological risk factors which are associated with its initiation and progression. ${ }^{7}$ Caries prevalence is high and still increasing in some developing countries, especially among urban children, while its decline has been reported in many industrialized countries during the last 3 decades. ${ }^{8}$ In recent studies, socioeconomic factors have been identified as predisposing factors in the development of both dental caries and periodontal disease. ${ }^{9}$ The WHO recommends basic oral health surveys in five selected age groups (i.e. 5, 12, 17-18, 35-44 and 65-74 years) in order to estimate the magnitude of the problem and to plan intervention activities. ${ }^{10}$ Economic improvement in a low-income country like India, Bangladesh may have an effect on dental health. Turag and Tongi are undergoing rapid urbanization, and this can be a risk factor for the increased prevalence of dental caries among the population. ${ }^{11,12}$ A previous study reveals that in Bangladesh, 12-year-old children were affected most by dental caries than adults at the age of 18 and 35 to 45 years in all socioeconomic groups. ${ }^{13}$ There is no doubt that dietary and oral hygiene habits are affected by income, education, and social environment. ${ }^{8}$ A study conducted in North 
Carolina showed convincingly that in Western countries people having low socioeconomic conditions tend to have more caries. ${ }^{13}$ The prevalence of dental caries is of great interest for long and is a principal subject of many epidemiological researches carried out all over the world. But in Bangladesh regarding this crucial condition, actual data is not available. A limited survey was done with school going children but real scenario was not reflected. Before this, no survey was conducted for madrasa going children. Therefore, keeping in mind the paucity of literature on dental problems among madrasa going children and the public. The health importance of dental caries, this study was planned to provide some information on the oral health needs of the target population. The main objective of this study determined the oral hygiene status and prevalence of DMFT among Madrasa going children at Turag, Dhaka, Bangladesh considers the age, ethnic group, socioeconomic status, oral hygiene habits, and dietary habits.

\section{METHODS}

A descriptive type of cross-sectional study was conducted to carry out the research. Six to twelve years of age madrasa going children residing at Turag and Tongi, Dhaka was the study population. The study was carried out by a purposeful selection of some madrasas in Turag, Dhaka. The study was carried out from May 2014 to November 2014 with sample size 251. Subjects were selected on the basis of inclusion criteria which include willingly agreeing to participate in the study and to sign the consent form. Children who were refusing to give informed consent and who were mentally retarded were excluded from this study. The research instruments used for data collection were a structured questionnaire and examination form that had been developed and modified from the literature reviews by researchers and consists of four sections. Section one, two and three consist of structured questionnaire and section four resemble to DMFT index (measured by clinical examination) using an examination form.

Section one: Sociodemographic factor which includes (a) Age, (b) sex, (c) parent's occupation, (d) monthly family income, (e) family member.

Section two: Oral hygiene practice which included (a) Tooth brushing, (b) frequency of brushing, (c) material used for brushing, (d) duration of tooth brushing, (g) use of toothpaste, (e) other preventive methods.

Section three: Oral health status related variable which includes (a) Gum bleeding, (b) bad breath, (c) visit to dentist, (d) reason to visit the dentist, (e) decayed teeth, (f) missing teeth, (g) filling teeth.

Section four: Interviewing with the questionnaire and oral examination was performed among the total sample of 251 children of different madrasas of Turag and
Tongi with the help of calibrated two dentists and three volunteers including researchers by interviewing and examination.

\section{RESULTS}

In this study, Table 1 showed sociodemographic information, where half of the respondents were female and the rests were male. More than half of the parents of respondents were service holder. Nearly half of the respondents' family belongs to BDT 10000 income group and very few were in above BDT 30000 income group. Table 2 showed the oral hygiene practice among the respondents. The majority of the respondents brushed

Table 1: Distribution of respondents by socioeconomic demographic variables

\begin{tabular}{lll}
\hline Variables & Frequency & Percentage \\
\hline $\begin{array}{l}\text { Sex } \\
\text { (a) Male }\end{array}$ & 114 & 45.4 \\
(b) Female & 137 & 54.6 \\
Parents occupation & & \\
(a) Businessman & 70 & 27.9 \\
(b) Service holder & 145 & 57.8 \\
(c) Worker & 21 & 8.4 \\
(d) Other & 15 & 6.0 \\
Family size & & \\
2-4 person & 99 & 39.4 \\
5-8 person & 148 & 59 \\
9 and above & 4 & 1.6 \\
Family income in BDT & & \\
10000 & 112 & 44.6 \\
above 10000-20000 & 52 & 20.6 \\
above 20000-30000 & 40 & 15.9 \\
above 30000 & 47 & 18.7 \\
\hline
\end{tabular}

Table 2: Distribution of respondents by oral hygiene practice

\begin{tabular}{lll}
\hline Variables & Frequency & Percentage \\
\hline $\begin{array}{l}\text { Daily tooth brushing } \\
\quad \text { Yes }\end{array}$ & 246 & 98 \\
$\quad$ No & 5 & 2 \\
Frequency of tooth brushing & & \\
$\quad 1$ times & 124 & 49.4 \\
2 times & 114 & 45.4 \\
$\quad 3$ times & 13 & 5.2 \\
Duration of brushing & & \\
$\quad$ minute & 33 & 13.1 \\
$\quad$ More than 1 minute & 67 & 26.7 \\
2 minutes & 50 & 19.9 \\
$\quad$ More than 2 minutes & 101 & 40.2 \\
Use of toothpaste & & \\
$\quad$ Rarely & 18 & 7.2 \\
$\quad$ Usually & 30 & 12.0 \\
$\quad$ Always & 203 & 80.8 \\
Use of other preventive method & & \\
$\quad$ Use & 13 & 5.2 \\
Did not use & 238 & 94.8 \\
\hline
\end{tabular}


Oral Health Status among Madrasa going Children

their teeth daily. About half of the respondents brushed only once a day followed by nearly half of the respondents brush twice a day. Nearly half of the respondents brush more than 2 minutes and a minor group brush for 1 minute. The majority of the respondents always used toothpaste and a few of them rarely used toothpaste. The majority of the respondents did not use other oral preventive methods. Table 3 reveals oral health status related information. Gum bleeding and bad breath were absent in most of the respondents. Most of the respondents never visited a dentist. One-third of the respondents who visited the dentist, visited for the tooth extraction purpose and very few of them visited for the checkup and the rest of them for gum bleeding. Table 4 gave DMFT related information. Around two-third of the respondents had decayed teeth. The majority of the respondents did not have any missing teeth and filled teeth. Table 5 showed that there was a highly significant association between

Table 3: Distribution of the respondents by oral health problems

\begin{tabular}{lll}
\hline Variables & Frequency & Percentage \\
\hline Gum bleeding & & \\
Present & 115 & 46 \\
Absent & 136 & 54 \\
Bad breath & & \\
Present & 97 & 38.6 \\
Absent & 154 & 61.4 \\
Visit to dentist & & \\
Yes & 89 & 35.5 \\
No & 162 & 64.5 \\
Reason to visit & & \\
Check up & 14 & 15.9 \\
Toothache & 21 & 23.9 \\
Gum bleeding & 6 & 6.8 \\
Tooth extraction & 31 & 35.2 \\
Others & 16 & 18.2 \\
\hline
\end{tabular}

Table 4: Distribution of respondents by Decayed (D), Missing (M), Filling $(F)$ teeth

\begin{tabular}{llllll}
\hline & \multicolumn{2}{c}{ Frequency } & & \multicolumn{2}{c}{ Percentage } \\
\cline { 2 - 3 } \cline { 6 - 6 } Variables & Present & Absent & & Present & Absent \\
\hline Decayed (D) & 176 & 75 & & 70.1 & 29.9 \\
Missing (M) & 11 & 240 & & 4.4 & 95.6 \\
Filling (F) & 5 & 246 & & 2 & 98 \\
DMFT & & 1.94 (mean) & & & \\
\hline
\end{tabular}

Table 5: Association between prevalence of caries teeth and monthly family income

\begin{tabular}{|c|c|c|c|c|c|c|}
\hline \multirow[b]{2}{*}{$\begin{array}{l}\text { Prevalence } \\
\text { of caries }\end{array}$} & \multicolumn{4}{|c|}{ Family monthly income (BDT) } & \multirow[b]{2}{*}{ Total } & \multirow[b]{2}{*}{$p$-value } \\
\hline & $\begin{array}{l}5000 \\
10000\end{array}$ & $\begin{array}{l}\text { Above } \\
10- \\
20000\end{array}$ & $\begin{array}{l}\text { Above } \\
20- \\
30000\end{array}$ & $\begin{array}{l}\text { Above } \\
30000\end{array}$ & & \\
\hline No caries & 26 & 10 & 20 & 19 & 75 & \\
\hline Caries & 86 & 42 & 20 & 28 & 176 & 0.001 \\
\hline Total & 112 & 52 & 40 & 47 & 251 & \\
\hline
\end{tabular}

* $p$-value from pearson $\chi^{2}$ test
Table 6: Association between prevalence of caries with frequency of tooth brushing per day

\begin{tabular}{|c|c|c|c|c|c|}
\hline \multirow{2}{*}{$\begin{array}{l}\text { Prevalence of } \\
\text { caries }\end{array}$} & \multicolumn{4}{|c|}{ Frequency of tooth brushing per day } & \multirow[b]{2}{*}{$p$-value } \\
\hline & 1 & 2 & 3 & Total & \\
\hline No caries & 38 & 29 & 8 & 75 & \\
\hline Caries & 86 & 85 & 5 & 176 & 0.026 \\
\hline Total & 124 & 114 & 13 & 251 & \\
\hline
\end{tabular}

* $p$-value from pearson $\chi^{2}$ test

prevalence of caries teeth and their monthly family income where the $p$ value is 0.001 . Table 6 revealed that there was a significant association between the frequency of tooth brushing per day and prevalence of caries, where $\mathrm{p}$-value is 0.026 .

\section{DISCUSSION}

Dental caries is the most prevalent chronic disease among the children in the global scenario. Dental caries is a disease which can be traced back to be as old as civilization with its evidence seen even in the skeletal remnants of prehistoric man but the prevalence of this disease has increased in the modern times on a worldwide basis. ${ }^{14} \mathrm{We}$ conducted this study in madrasa because as such up till now no study is performed focussing on madrasa going children. Several oral health programs were performed in schools, but madrasa going population were neglected most of the time. Many researchers focused on oral health status of school children in their study, but our study is focussed on only madrasa going students.

In the present study, the number of girls are slightly higher $(54.60 \%)$ than the boys $(45.40 \%)$ respectively. Out of them, dental caries were significantly more prevalent in girls than in boys which suggested that dental caries show some predilection for sex. The same findings were detected by a previous study in Bangladesh ${ }^{15}$ whereas opposite scenario was shown by other studies in west Germany, but in that study the age of the children were under 5 years. ${ }^{16}$ The study revealed that out of all respondents, $70.1 \%$ had dental caries, which is close to a study which was conducted in Chidambaram $(63.80 \%){ }^{17}$ whereas another study conducted in Nepal showed that $67 \%$ of the respondents had caries, which is almost similar to our finding. ${ }^{18}$ Female children had higher DMFT score, i.e., 2.10 as compared to males with DMFT score of 1.76 and mean DMFT score was 1.94. Compared to other studies in Iran, female children had higher DMFT (1.19) than male children (1.09) and mean DMFT was $1.62 .{ }^{19}$ Studies from Nepal also showed that mean DMFT score (0.84) with $42 \%$ caries prevalence, which is different from our study because our study focussed on neglected and deprived group of population. ${ }^{20}$ Data from Australia health and welfare institute, mean DMFT score among this age group was 1.11 because of their 
better lifestyle and more health awareness. ${ }^{21}$ Among the respondents, $98 \%$ brushed their teeth daily which is better than studies which was conducted in Iran $(69 \%)$, might be due to lack of awareness regarding tooth brushing. ${ }^{19}$ Among them, $49.4 \%$ of the respondents brushed their teeth once daily and $45.4 \%$ twice daily as compared to studies from Thailand where only $77 \%$ of respondents brush their teeth daily. Another study in India shows that $69.7 \%$ of respondents brush their teeth twice daily. ${ }^{22}$ In our study, $80.9 \%$ always used toothpaste, whereas other studies showed that $70 \%$ did not use toothpaste ${ }^{25}$ while another study showed that $89.33 \%$ use toothpaste regularly. ${ }^{22,23}$ We found that $46 \%$ of the respondents had gum bleeding problems and $38.6 \%$ of the respondents had bad breath compared to studies from India where only $10 \%$ of respondents had gum bleeding problems and $8.66 \%$ had bad breath because of their awareness activity. In this study, $35.5 \%$ of the respondents visited dentist compared to another studies conducted in Nepal where only $7 \%$ of respondents visited dentist. ${ }^{20}$ Among them, $35.2 \%$ of the respondents visited a dentist for tooth extraction, $23.9 \%$ for toothache, $94.8 \%$ of the respondents did not use oral preventive measure, $95.6 \%$ of the respondents did not have any missing teeth with mean of 1.04 compared to data from Australia (0.04), ${ }^{21}$ and $98 \%$ of the respondents had not filled tooth. In this study, we found highly significant association between prevalence of caries teeth and their monthly family income where p-value is 0.001 and significant association between frequency of tooth brushing per day and prevalence of caries where $p$-value is 0.026 which is similar to another studies conducted in Mangalore city. ${ }^{24}$ But another two studies did not find any significant association. ${ }^{25,26}$ These data on oral health status and prevalence of DMFT helps to determine the appropriate treatment plan for children. Besides, there is an urgent need for periodic surveys so that the outcomes of preventive programs can be monitored, as recommended by WHO. This study has certain limitations which should be taken into consideration when interpreting the results. Since the study was conducted as a crosssectional survey, sample size is small, so that data will not represent the real-time situation of the whole country.

\section{CONCLUSION}

A study on oral health assessment and dental health education of children at an early age helps in improving preventive dental behavior and attitudes, which is beneficial for a lifetime. This can be achieved by educating the uneducated and less aware parents about dental health through madrasa dental health programs. For the benefit of a community, dental health programs have to be con- ducted repeatedly in order to reach the goals of the WHO. Parents should be made aware of the brushing methods, and usage of pits and fissure sealants and the importance of preventive measures for the children. The rationale of the madrasa dental health program is to improve and motivate the parents and children regarding their dental health treatment needs.

Dental plaque biofilm cannot be eliminated. However, the pathogenic nature of the dental plaque biofilm can be reduced by reducing the bio-burden (total microbial load and different pathogenic isolates within that dental plaque biofilm) and maintaining a normal flora. Recent research in context to oral hygiene especially related to combating dental calculus will be a vital step for future directions that will change the face of preventive dentistry. ${ }^{27}$

\section{REFERENCES}

1. Gee KA. Achieving gender equality in learning outcomes: Evidence from a non-formal education program in Bangladesh. Int J Edu Dev 2014;40:206-207.

2. Asadullah MN, Chaudhury N, Dar A. Student achievement conditioned upon school selection: Religious and secular secondary school quality in Bangladesh. Econ Edu Rev 2007; 26(6):648-659.

3. Petersen PE, Yamamoto T. Improving the oral health of older people: the approach of the WHO Global Oral Health Programme. Community Dent Oral Epidemiol 2005;33(2):81-92.

4. Beal JF, James PMC. Social differences in the dental conditions and dental needs of 5-year-old children in four areas of the West Midlands. Br Dent J 1970;129(7):313-318.

5. Selwitz RH, Ismail AI, Pitts NB. Dental caries. The Lancet 2007;369(9555):51-59.

6. Yee $\mathrm{R}$, Sheiham A. The burden of restorative dental treatment for children in third world countries. Int Dent J 2002; 52(1):1-9.

7. Petersen PE. The World Oral Health Report 2003: continuous improvement of oral health in the 21st century-The approach of the WHO Global Oral Health Programme. Community Dent Oral Epidemiol 2003:31(1),3-24.

8. Petersen PE, Hoerup N, Poomviset N, Prommajan J, Watanapa A. Oral health status and oral health behaviour of urban and rural schoolchildren in Southern Thailand. Int Dent J 2001; 51(2):95-102.

9. Sgan-Cohen HD, Lipsky R, Behar R. Caries, diet, dental knowledge and socioeconomic variables in a population of 15-year-old Israeli schoolchildren. Community Dent Oral Epidemiol 1984;12(5):332-336.

10. Sumit K, Kumar S, Saran A, Dias FS. Oral health care delivery systems in India: An overview. Int J Basic Appl Med Sci 2013; 3:171-178

11. Varenne B, Petersen PE, Ouattara S. Oral health status of children and adults in urban and rural areas of Burkina Faso, Africa. Int Dent J 2004;54(2):83-89.

12. Jamel H, Plasschaert A, Sheiham A. Dental caries experience and availability of sugars in Iraqi children before and after the United Nations sanctions. Int dent J 2004;54(1):21-25.

13. Disney J, Graves R, Stamm J, Bohannan H, Abernathy J. The University of North Carolina Caries Risk Assessment Study. II. Baseline Caries Prevalence. J Public Health Dent 1990; 50(3):178-185. 
14. Joshi N, Rajesh R, Sunitha M. Prevalence of dental caries among school children in Kulasekharam village: A correlated prevalence survey. J Indian Soc Pedod Prev Dent 2005; 23(3):138

15. Rahman SS, Rasul CH, Kashem MA, Biswas SS. Prevalence of dental caries in the primary dentition among under five children. Bangladesh Med J (Khulna) 2012;43(1-2):7-9.

16. Zerfowski M, Koch MJ, Niekusch, U, Staehle HJ. Caries prevalence and treatment needs of 7-to 10-year-old school children in southwestern Germany. Community Dent Oral Epidemiol 1997;25(5):348-351.

17. Moses J, Rangeeth BN, Gurunathan D. Prevalence of dental caries, socio-economic status and treatment needs among 5 to 15 year old school going children of Chidambaram. J Clin Diagnostic Res 2011;5(1):146-151.

18. Yee R, McDonald N. Caries experience of 5-6-year-old and 12-13-year-old schoolchildren in central and western Nepal. International Dent J 2002;52(6):453-460.

19. Motlagh MG, Khaniki GRJ, Adiban H. Investigation of Dental Caries Prevalence among 6-12 year old Elementary School Children in Andimeshk. Iran J Med Sci 2007; 7(1):116-120.

20. Dixit LP, Shakya A, Shrestha M, Shrestha A. Dental caries prevalence, oral health knowledge and practice among indigenous Chepang school children of Nepal. BMC Oral Health 2013;13(1):20.
21. Hallett KB, O'Rourke PK. Dental caries experience of preschool children from the north Brisbane region. Aust Dent J 2002;47(4):331-338.

22. Mehta A, Kaur G. Oral health-related knowledge, attitude, and practices among 12-year-old schoolchildren studying in rural areas of Panchkula, India. Ind J Dent Res 2012; 23(2):293

23. Östberg AL, Jarkman K, Lindblad U, Halling A. Adolescents' perceptions of oral health and influencing factors: a qualitative study. Acta Odontol 2002;60(3):167-173.

24. Ainamo J, Parviainen K. Occurrence of plaque, gingivitis and caries as related to self-reported frequency of toothbrushing in fluoride areas in Finland. Community Dent Oral Epidemiol 1979;7(3):142-146.

25. Sudha P, Bhasin S, Anegundi RT. Prevalence of dental caries among 5-13-year-old children of Mangalore city. J Ind Soc Pedod Prev Dent 2005;23(2):74.

26. Mafuvadze, BT, Mahachi L, Mafuvadze B. Dental caries and oral health practice among 12 year old school children from low socio-economic status background in Zimbabwe. Pan Afr Med J 2013;14:164.

27. Saini R. A prospective experimental comparative study on the clinical effects of calculus dissolution based oral rinse in gingivitis patients. Int J Experiment Dent Sci 2015;4(1):33-39. 